\title{
A Study of the dosage and duration for levobupivacaine infusion by the caudal-epidural route in infants aged 3-6 months
}

DOI:

10.1111/pan.13548

\section{Document Version}

Accepted author manuscript

Link to publication record in Manchester Research Explorer

Citation for published version (APA):

Vashisht, R., Bendon, A., Okonkwo, I., Patel, D., Fullwood, C., Ogungbenro, K., Aarons, L., \& Darwich, A. (2019). A Study of the dosage and duration for levobupivacaine infusion by the caudal-epidural route in infants aged 3-6 months. Pediatric Anesthesia, 29(2), 161-168. https://doi.org/10.1111/pan.13548

\section{Published in:}

Pediatric Anesthesia

\section{Citing this paper}

Please note that where the full-text provided on Manchester Research Explorer is the Author Accepted Manuscript or Proof version this may differ from the final Published version. If citing, it is advised that you check and use the publisher's definitive version.

\section{General rights}

Copyright and moral rights for the publications made accessible in the Research Explorer are retained by the authors and/or other copyright owners and it is a condition of accessing publications that users recognise and abide by the legal requirements associated with these rights.

\section{Takedown policy}

If you believe that this document breaches copyright please refer to the University of Manchester's Takedown Procedures [http://man.ac.uk/04Y6Bo] or contact uml.scholarlycommunications@manchester.ac.uk providing relevant details, so we can investigate your claim.

\section{OPEN ACCESS}




\section{A Study of the dosage and duration for levobupivacaine infusion by the caudal-epidural route in infants aged 3-6 months}

\begin{tabular}{|c|c|}
\hline Journal: & Pediatric Anesthesia \\
\hline Manuscript ID & PAN-2018-0260.R2 \\
\hline Wiley - Manuscript type: & Research Report \\
\hline $\begin{array}{l}\text { Date Submitted by the } \\
\text { Author: }\end{array}$ & 05-Nov-2018 \\
\hline Complete List of Authors: & $\begin{array}{l}\text { Vashisht, Rita; Royal Manchester Children's Hospital, Paediatric } \\
\text { Anaesthesia } \\
\text { Bendon, Anju Anne; Royal Manchester Childrens Hospital, Anaesthesia } \\
\text { Okonkwo, Ijeoma; Royal Manchester Children's Hospital, Anaesthesia } \\
\text { Patel, Davandra; Royal Manchester Children's Hospital, Paediatric } \\
\text { Anaesthesia } \\
\text { Fulwood, Catherine; Central Manchester University Hospitals NHS } \\
\text { Foundation Trust, Biostatistics, Research and Innovation } \\
\text { Ogungbenro, Kayode; University of Manchester Pharmacy School, } \\
\text { Department of Cancer Pharmacometrics } \\
\text { Darwich, Adam; University of Manchester Pharmacy School, Centre for } \\
\text { Applied Pharmacokinetic Research } \\
\text { Aarons, Leon; University of Manchester Pharmacy School, Centre for } \\
\text { Applied Pharmacokinetic Research }\end{array}$ \\
\hline Key Words: & $\begin{array}{l}\text { infant }<\text { Age, local anesthetics < Drugs, regional < Pain, Measurement, } \\
\text { pharmacokinetics < Drugs }\end{array}$ \\
\hline
\end{tabular}

\section{SCHOLARONE


A Study of the dosage and duration for levobupivacaine infusion by the caudal-epidural route in infants aged 3-6 months

Rita Vashisht ${ }^{1}$, Anju A Bendon ${ }^{1}$, Ijeoma Okonkwo ${ }^{1}$, Davandra Patel ${ }^{1}$, Catherine Fullwood ${ }^{2}$, Kayode Ogungbenro $^{3}$, Leon Aarons $^{3}$, Adam S. Darwich ${ }^{3}$

1. Department of Paediatric Anaesthesia,

Royal Manchester Children's Hospital,

Manchester University NHS Foundation Trust,

Oxford Road, Manchester M13 9WL,

United Kingdom

2. Biostatistics, The University of Manchester;

Research and Innovation;

Nowgen Building,

Manchester University NHS Foundation Trust,

Grafton St, Manchester M13 9WU,

United Kingdom

3. Centre for Applied Pharmacokinetic Research,

School of Health Sciences,

The University of Manchester,

Stopford Building, Oxford Road, Manchester M13 9PT,

United Kingdom

Address for Correspondence:

Dr Rita Vashisht,

Department of Paediatric Anaesthesia,

Royal Manchester Children's Hospital,

Manchester University NHS Foundation Trust,

Oxford Road, Manchester M13 9WL,

United Kingdom

Email: rita.vashisht@mft.nhs.uk

Phone: 00441617011263 


\title{
What is already known?
}

- Levobupivacaine is highly bound to $\alpha_{1}$-acid glycoprotein, an acute phase protein, where unbound levobupivacaine is responsible for toxicity.

- While pharmacokinetics of racemic bupivacaine has been studied for infusions up to 48 hours in neonates and up to 4 hours in infants, pharmacokinetics for levobupivacaine has only been studied after a single shot caudal administration.

\section{What this article adds}

- In infants aged 3-6 months, using current recommended dosing schedules of levobupivacaine, total drug concentrations continue to rise during the 48 hour caudal-epidural infusion due to rising $\alpha_{1}$-acid glycoprotein concentrations; however, total drug concentrations remain below suggested toxic concentrations.

- Following major surgery in infants, $\alpha_{1}$-acid glycoprotein levels increase during the first 72 hours.

- Pharmacokinetic modelling shows that unbound levobupivacaine concentrations do not rise beyond the concentrations reached immediately after the loading dose and the unbound drug remains unaffected by $\alpha_{1}$-acid glycoprotein.

\begin{abstract}
Aim: To investigate total serum levobupivacaine concentrations after a caudal-epidural loading dose followed by a maintenance infusion in infants aged 3-6 months over 48 hours.

Background: The local anaesthetic, levobupivacaine, is the safer enantiomer of racemic bupivacaine. Present protocols for levobupivacaine are based on studies and pharmacokinetic modelling with racemic bupivacaine. This study will inform clinical practice in this age group and validate the pharmacokinetic model for levobupivacaine infusions in infants, aged 3-6months.

Methods: The clinical trial was conducted in 8 infants aged 3-6 months, undergoing bladder exstrophy repair. Pharmacokinetic modelling allowed optimisation of clinical sampling to measure total levobupivacaine and $\alpha_{1}$-acid glycoprotein and prediction of the effect of $\alpha_{1}$-acid glycoprotein on levobupivacaine plasma protein binding.

Results: The observed median total levobupivacaine serum concentration was $0.30 \mathrm{mg} . \mathrm{L}^{-1}$ (range: $0.20-0.70 \mathrm{mg} . \mathrm{L}^{-1}$ ) at 1 hour after the loading dose of $2 \mathrm{mg} \cdot \mathrm{kg}^{-1}$. The median total levobupivacaine concentration after 47 hours of infusion, at 0.2 $\mathrm{mg} . \mathrm{h}^{-1} \cdot \mathrm{kg}^{-1}$, was $1.21 \mathrm{mg} . \mathrm{L}^{-1}\left(0.07-1.85 \mathrm{mg} . \mathrm{L}^{-1}\right)$. Concentrations of $\alpha_{1}$-acid glycoprotein were found to rise throughout the study period. Pharmacokinetic modelling suggested that unbound levobupivacaine quickly reached steady state at a concentration of approximately $0.03 \mathrm{mg} . \mathrm{L}^{-1}$.
\end{abstract}


Conclusion: This study examines the pharmacokinetics of levobupivacaine after a loading dose (given over 5 minutes) followed by a maintenance infusion in infants 3-6 months. The study allows the development of a pharmacokinetic model, combining levobupivacaine and $\alpha_{1}$-acid glycoprotein data. Modelling indicates that unbound levobupivacaine quickly reaches steady state once the infusion is started. Simulations suggest that it may be possible to continue the infusion beyond 48 hours.

\section{Keywords:}

levobupivacaine; $\alpha_{1}$-acid glycoprotein; infants; caudal-epidural infusion; bladder exstrophy; pharmacokinetics

\section{List of abbreviations:}

AAG: $\alpha_{1}$-acid glycoprotein

LBU: levobupivacaine

CYP: cytochrome P450

$\mathrm{CL}_{\mathrm{u}}$ : unbound clearance

F: bioavailability

$\mathrm{k}_{\mathrm{a}}$ : rate of absorption

$\mathrm{R}_{0}$ : rate of infusion

$\mathrm{V}_{\mathrm{u}}$ : unbound volume of distribution

$\mathrm{K}_{\mathrm{D}}$ : dissociation constant

$\mathrm{C}_{\text {tot, LBU: }}$ Concentration of total levobupivacaine

$\mathrm{C}_{\mathrm{u}, \mathrm{LBU}}$ : Concentration of unbound levobupivacaine

\section{Background}

Levobupivacaine is the S (-) enantiomer of racemic bupivacaine, displaying a lower risk of cardiovascular and central nervous system toxicity while still retaining local anaesthetic potency. ${ }^{1}$ In paediatric patients, the elimination increases with age and reaches $80 \%$ of the adult capacity by the age of 6 months. ${ }^{2}$ Present protocols of caudal-epidural infusions of levobupivacaine are based upon studies of bupivacaine and pharmacokinetic modelling. ${ }^{3,4,5}$ Previous studies of levobupivacaine are limited to examining serum concentrations of levobupivacaine in infants following a single caudalepidural bolus dose..$^{67,8}$ A bolus dose followed by an infusion for 24 hours has been studied in infants over 6 months. ${ }^{9}$ At 
the same time, studies of racemic bupivacaine in infants ${ }^{10}$ and neonates ${ }^{11}$, with infusion periods of 12 and $48 \mathrm{~h}$, respectively, have raised concerns over its safety in this age group. ${ }^{4}$

A study of serum concentrations of levobupivacaine after a loading dose followed by an infusion for 48 hours, in infants aged 3-6 months, would help inform clinical practice. By restricting the age group we focus on the maturation of the liver and clearance with age in these infants. Since the unbound local anaesthetic is responsible for toxicity, the degree of binding to the acute phase protein, $\alpha_{1}$-acid glycoprotein (AAG), should be considered.

Bladder Exstrophy is a rare congenital abnormality, with an incidence of $1: 45,500^{12}$, requiring major corrective surgery in early infancy. This involves closure of the bladder and abdominal wall. The splayed pubic bones are brought together by an anterior osteotomy and an external pelvic fixator remains in situ for 4-6 weeks. Surgery takes 6-8 h and infants can be extubated at the end of the procedure if a caudal-epidural catheter has been sited and an infusion of levobupivacaine provides postoperative pain. At present clinicians are limited by the volume, concentration and duration of the infusions due to concerns regarding cardiovascular and central nervous system toxicity.

Here we present a clinical trial examining serum concentrations of total levobupivacaine and AAG in this group of patients. Aims:

\section{To use pharmacokinetic analysis to predict the unbound levobupivacaine concentrations for the study protocol \\ - $\quad$ To use pharmacokinetic modelling and consider the safety of alternative dosing schedules e.g. increasing the loading dose and an earlier onset of the maintenance infusion.}

\section{Methods}

This study was conducted as a Phase II/III clinical trial (EudraCT no: 2015-000393-34) with the MHRA (21387/0235/001-0001) and Northwest Ethics Committee approval (15/NW/0240). The trial was conducted in compliance with the protocol, following GCP guidelines. Written informed consent was obtained from parents. The study population consisted of infants aged three to six months undergoing repair of Bladder Exstrophy.

The exclusion criteria were lack of consent, hypersensitivity to local anaesthetics, history of seizures or neurological disorders, bradyarrhythmias, blood clotting disorders, congenital abnormalities precluding regional anaesthesia.

The trial was designed in several stages. A literature-based joint LBU and AAG pharmacokinetic model was developed to predict the impact of changes of AAG concentrations, associated with surgery, on total levobupivacaine 
concentrations. Prospective pharmacokinetic simulations of levobupivacaine and AAG were carried out in Matlab R2012a (Mathworks, Natick, MA) to inform the blood sampling strategy. This was based on a population pharmacokinetic model of unbound levobupivacaine following a caudal injection of levobupivacaine 2 mg.kg-1 given over 30 seconds, in infants undergoing sub-umbilical surgery. ${ }^{8}$ The model was modified to account for time-dependent changes in levels of AAG following surgery. ${ }^{14}$ It allowed the estimation of optimal sampling time points, limiting blood sample volumes in accordance with the WHO guidance. ${ }^{15}$ Optimal design evaluations were performed using PopDes(The University of Manchester; Matlab: http://research.bmh.manchester.ac.uk/capkr/softwaretools/) based on the preliminary model. ${ }^{16}$

Infants were recruited over a period of 24 months (June 2015 - June 2017). The clinical data collected were then used to develop a novel population pharmacokinetic model of levobupivacaine and AAG to simulate alternative dosing protocols.

\section{Conduct of the study}

At preoperative assessment a week prior to surgery, details of the planned anaesthetic and clinical trial were discussed and a written information sheet provided. Consent was obtained on the morning of surgery. Anaesthesia was induced with sevoflurane in oxygen and atracurium $0.5 \mathrm{mg} \cdot \mathrm{kg}^{-1}$ was given to facilitate orotracheal intubation. Anaesthesia was maintained using sevoflurane in oxygen and air through a circle system. Invasive arterial monitoring and a central venous line (4 Fr, $5 \mathrm{~cm}$ double lumen) were established. An Oesophageal Doppler cardiac output monitor (Deltex Medical) was also used to assist fluid management. The caudal space was imaged using ultrasound and an Arrow, flexitip ${ }^{\circledR}$ reinforced catheter was inserted. This was tunnelled to the right flank and the catheter tip position was confirmed using fluoroscopy.

\section{Caudal Epidural Dosing Regime}

A loading dose of levobupivacaine $0.25 \% 2 \mathrm{mg} \cdot \mathrm{kg}^{-1}\left(0.8 \mathrm{~mL} \cdot \mathrm{kg}^{-1}\right)$ was injected over 5 minutes (start of loading dose was time zero). A maintenance infusion of levobupivacaine $0.125 \% 0.2 \mathrm{mg} \cdot \mathrm{kg}^{-1} \cdot \mathrm{h}^{-1}$ with clonidine $\left(1.5 \mathrm{mcg}^{\mathrm{m}} \mathrm{mL}^{-1}\right)^{17}$ was started one hour after time zero and run for $47 \mathrm{~h} .4 .{ }^{11}$ All infants also received a remifentanil infusion $\left(25 \mathrm{mcg} \cdot \mathrm{ml}^{-1}\right)$ intraoperatively which was titrated as required. Additional intraoperative medications included paracetamol $\left(10 \mathrm{mg} \cdot \mathrm{kg}^{-}\right.$ 
$\left.{ }^{1}\right)$, ondansetron $\left(0.1 \mathrm{mg} \cdot \mathrm{kg}^{-1}\right)$ and dexamethasone $\left(0.1 \mathrm{mg} \cdot \mathrm{kg}^{-1}\right)$. Plasmalyte 148 was used as the intraoperative fluid and arterial blood gas results were used to monitor blood sugar levels. Infants were extubated at the end of surgery and managed in the paediatric critical care unit (PCCU) while the caudal-epidural catheter was still in situ. Regular postoperative analgesia was prescribed: intravenous paracetamol $10 \mathrm{mg} \cdot \mathrm{kg}^{-1}$ every $6 \mathrm{~h}$ and per oral ibuprofen $5 \mathrm{mg} . \mathrm{kg}^{-1}$ every 8 h. Oral morphine 50 mcg. $\mathrm{kg}^{-1}, 4$ hourly was prescribed for FLACC $>4$. Post-operative pain scores were noted hourly (FLACC scale: face, legs, activity, cry, consolability). The caudal-epidural infusion was stopped after 47 hours and blood samples were collected for analysis up to 72 hours after the loading dose.

\section{Blood sampling}

Blood samples were taken from the indwelling central venous catheter. Dead space sampling was performed and the volume from the dead space was injected back using antiseptic non-touch technique. No intravenous fluids were administered through the central line. The samples were collected in plain glass pyrex tubes for levobupivacaine ( $2 \mathrm{~mL} / \mathrm{sample})$ and lithium heparin for AAG $(0.8 \mathrm{~mL} /$ sample). The samples were labelled 1 to 9 with sampling time points at $0.25,1,2,4,12,36,48,60$ and 72 hours. (Table S1).

\section{Blood Sample Management}

All samples were anonymised for analysis, identifiable only by a unique number to allow data linkage. Blood samples were stored at $4^{\circ} \mathrm{C}$ then centrifuged in the laboratory. The serum was then stored at $-80^{\circ} \mathrm{C}$.

Analysis of levobupivacaine was undertaken in a CPA accredited laboratory (Department of Clinical Pathology, Queens Medical Centre, Nottingham) where they were centrifuged at 2,500 rpm for 10 minutes. Levobupivacaine was analysed in a matrix of human plasma using a developed and validated gas chromatography-mass spectrometry (GC-MS) approach. Levobupivacaine measurements were made according to published methods. ${ }^{18,19} 0.5 \mathrm{~mL}$ of serum was alkalinised with sodium hydroxide with extraction of levobupivacaine into diethyl ether. The extract was then evaporated to dryness under nitrogen prior to reconstitution in methanol and analysis by GC-MS. The lower limit of quantification (LLOQ) of the assay was $0.1 \mathrm{mg} \cdot \mathrm{L}^{-1}$ and the linear range of the assay without prior dilution was $10 \mathrm{mg} . \mathrm{L}^{-1}$. Ropivacaine was used as the internal standard. The AAG samples were analysed in the biochemistry laboratory at Royal Manchester Children's Hospital.

\section{Statistical analysis}


This study was conducted as a Phase II/III clinical trial. It was designed as an exploratory observational study to develop the pharmacokinetic model in this age group with an aim to be used to inform further studies. It aimed to recruit 10 infants over a 2 year period, with a final sample of 8 infants. All parents approached, consented to participate in the trial. Descriptive statistics and graphs were used to explore the serum concentration-time profiles and the between patient variability. Rv3.0.2 software (https://www.r-project.org/) was used for this descriptive and graphical analysis. ${ }^{20}$

\section{Data management}

All data were anonymised and only identifiable by a unique study number allocated at recruitment. Data collection was performed by one of the investigators and stored in both paper and electronic form.

\section{Pharmacokinetic Analysis}

Population pharmacokinetic modelling was carried out to analyse the generated clinical data (total levobupivacaine and AAG) from 8 infants. This was performed using NONMEM 7.3 (ICON plc, Dublin, Ireland). Identifiability analysis of the proposed AAG and levobupivacaine models was carried out using the software DAISY (Differential Algebra for Identifiability of Systems; University of Cagliari, Cagliari, Italy) ${ }^{21}$ and the models were found to be globally identifiable. Due to the limited dataset ( $\mathrm{n}$ patients $=8$ ), covariate analysis was not considered. Data below the LLOQ were included in the analysis ( 7 out of a total 66 data points were used in analysis, or 10.6\%) as per the all data approach recommended by Keizer et al..$^{22,23}$

In one of the infants (infant 3), the levobupivacaine infusion was stopped after approximately $12 \mathrm{~h}$. Sampling points beyond $12 \mathrm{~h}$ were excluded.

The AAG model was developed to describe the time-dependent change in AAG levels following surgery. This was followed by the development of the population pharmacokinetic model to describe total levobupivacaine concentrations following continuous caudal-epidural infusion. Diagrams of the pharmacokinetic models are displayed in Figure 1.

The levobupivacaine pharmacokinetic model was parameterised to describe the unbound parameters $\left(\mathrm{k}_{\mathrm{a}}, \mathrm{CL}_{\mathrm{u}} / \mathrm{F}\right.$ and $\mathrm{V}_{\mathrm{u}} / \mathrm{F}$ ), as the observed data indicated time-dependent variations in pharmacokinetic parameters based on total concentrations. Due to the inability to measure unbound levobupivacaine in this study, total concentrations were derived using the post-hoc individual parameter estimates for the AAG model together with a calculated $\mathrm{K}_{\mathrm{D}}$ (plasma protein binding dissociation constant) with a geometric mean of $32.6 \mathrm{mg} . \mathrm{L}^{-1}$ (geometric standard deviation: $1.1 \mathrm{mg} . \mathrm{L}^{-1}$ ) derived 
from adult data digitised from Veering et al. ${ }^{24}$ Digitisation was carried out using GetData Graph Digitizer (S. Federov; see Supplementary Material for further information).

Model performance was evaluated by examining visual predictive checks (VPCs, number of simulations $=10,000)$ and goodness-of-fit (GOF) plots (Figure S2, Supplementary Material). Alternative dosing strategies were simulated in Matlab using the final model.

\section{Results}

Eight infants aged 3-6 months (mean age: 5 months, standard deviation (SD): 0.5 months, range: $4-5.9$ months at the time of surgery) were recruited over a period of 24 months. There were five boys and three girls. Mean bodyweight was $6.90 \mathrm{~kg}$ (SD: 0.96 , range: $5.97-8.67 \mathrm{~kg}$ ). There were no associated congenital abnormalities other than bladder exstrophy and biochemistry was normal. A caudal-epidural loading dose (short infusion over 5 minutes) was given followed 60 minutes later by a $47 \mathrm{~h}$ maintenance infusion. The effect of the acute phase protein, AAG, on the serum concentrations of total levobupivacaine was investigated. Complete data were available for 6 out of $8(75 \%)$ infants. For one of the infants (infant 5), samples at $60 \mathrm{~h}$ and $72 \mathrm{~h}$ could not be obtained due to a blocked central line. Another infant (infant 3 ) had their caudal catheter removed at $12 \mathrm{~h}$ as they developed respiratory distress and high temperature and needed to be reintubated. The FLACC pain scores for all the infants remained below 4 during the trial period. All infants received a blood transfusion, mean volume of $13.4 \mathrm{~mL} \cdot \mathrm{kg}^{-1}$ (range of $60-130 \mathrm{~mL}$ ) approximately between $2 \mathrm{~h}$ and $4 \mathrm{~h}$. Intraoperative fluids used were Plasmalyte 148, Plasmalyte with Dextrose 5\% if required and Gelofusine. No Albumin was used. Gelofusine: mean of 12.4 mL.kg-1 (range 60-130 mL), crystalloid mean of $64.2 \mathrm{~mL}^{-\mathrm{kg}^{-1}}$ (range $395-504 \mathrm{~mL}$ ).

The results from the analysis of total levobupivacaine concentrations at $1 \mathrm{~h}$ showed a median total serum concentration of $0.3 \mathrm{mg} . \mathrm{L}^{-1}$ (range: $0.20-0.70 \mathrm{mg} . \mathrm{L}^{-1}$ ) after the 5 minute short infusion loading dose of $2 \mathrm{mg}^{\mathrm{kg}} \mathrm{kg}^{-1}$. The median total levobupivacaine concentration after $47 \mathrm{~h}$ of the maintenance infusion $\left(0.2 \mathrm{mg} \cdot \mathrm{kg}^{-1} \cdot \mathrm{h}^{-1}\right)$ was $1.21 \mathrm{mg} \cdot \mathrm{L}^{-1}$ (range: $0.07-1.85$ mg.L $\mathrm{L}^{-1}$ ) (Figure 2). Total levobupivacaine concentrations increased throughout the infusion period and serum AAG concentrations continued to rise up to $72 \mathrm{~h}$ (Figure 3). This showed consistency with the predicted plasma concentrationtime profiles that were simulated prospectively to inform the study design (Figure S2, Supplementary Material). The final AAG model was modified from a Hill function to an empirical precursor model with an interaction term to best describe the observed data in this study (Figure 1; Equations S2 and S3 Supplementary Material, and Table1). The population 
pharmacokinetic analysis based on unbound parameterisation showed levobupivacaine to display one compartmental disposition (Figure 1; Equations S4-S6, Supplementary Material) with slow release from the site of administration to the systemic circulation with an estimated absorption rate constant $\left(\mathrm{k}_{\mathrm{a}}\right)$ of $0.15 \mathrm{~h}^{-1}$. The average apparent unbound clearance $\left(\mathrm{CL}_{\mathrm{u}} / \mathrm{F}\right)$ and apparent unbound volume of distribution $\left(\mathrm{V}_{\mathrm{u}} / \mathrm{F}\right)$ were $61.30 \mathrm{~L} \cdot \mathrm{h}^{-1}$ and $1.05 \mathrm{~L}$, respectively (Table 1). Figures 2 and 3 show the visual predictive checks (number of simulations=10,000) for total levobupivacaine and AAG over time, respectively.

Pharmacokinetic modelling suggested that unbound levobupivacaine levels quickly reached steady state concentrations after the short infusion, loading dose of levobupivacaine $0.25 \%\left(2 \mathrm{mg} \cdot \mathrm{kg}^{-1}\right)$. The simulated unbound levels were then maintained throughout the infusion period at around $0.03 \mathrm{mg} \cdot \mathrm{L}^{-1}$ (Figure 4).

We also simulated an alternative dosing protocol which is the same as that used in infants over $6 \mathrm{months}\left(2.5 \mathrm{mg} \cdot \mathrm{kg}^{-1}\right.$ loading dose) followed immediately by a maintenance infusion of $0.2 \mathrm{mg} \cdot \mathrm{kg}^{-1} \cdot \mathrm{h}^{-1}$ ). Simulated concentration-time profiles (Figure 5) using this alternative dosing were very similar to the standard protocol and showed only a slight increase in unbound concentrations (remaining below $0.08 \mathrm{mg} \cdot \mathrm{L}^{-1}$ ).

\section{Discussion}

This clinical trial investigates serum concentrations of the local anaesthetic levobupivacaine in infants aged 3-6 months.

Other studies $5,7,8,10,11$ have been limited due to the difficulty in obtaining serial samples from infants over a prolonged time period. Due to these limitations clinical questions regarding the concentration of the loading dose and timing of the maintenance infusion have so far remained unanswered and our study attempts to answer these questions.

We chose to conduct this study in infants with bladder exstrophy who require major corrective surgery for the abnormality at an early age. Central venous access is routinely used for monitoring and was used to obtain blood samples. A caudal-epidural catheter is also recommended for pain relief. ${ }^{25}$ These patients may potentially benefit from higher doses of local anaesthetic, particularly at the time of the osteotomy. However, clinicians are limited by existing dosing protocols due to the possibility of central nervous system and cardiovascular side effects, with higher doses and longer duration of the infusion in infants. Choosing our particular group of infants with a rare congenital abnormality (57 infants at our centre per year) limited recruitment to only 8 infants. 
The small number of study participants prohibited any investigation of covariate associations with pharmacokinetic parameters and resulted in a potential exaggeration of variability in the simulated AAG and levobupivacaine concentration levels. This is not uncommon when analysing datasets consisting of a small number of study participants.

Levobupivacaine is extensively metabolised by cytochrome P450 (CYP) 3A4 and 1A2.1,2 Chalkiadis et al. found bodyweight, normalised clearance of levobupivacaine to increase following birth and approach $80 \%$ of adult values at six months of age. ${ }^{2}$

Our results showed that the serum concentration of total levobupivacaine increased after the initial loading dose and continued to rise throughout the infusion period. When the infusion was stopped the levels fell rapidly (Figure 2). This confirms findings by Larsson et al. with bupivacaine in neonates receiving epidural infusions. ${ }^{11}$

Concentrations of AAG were shown to increase during the course of the surgery and appeared to plateau towards the end of the study period, which is consistent with previous studies. ${ }^{24}$ The magnitude of increase in AAG observed in this study is larger (approximately a 4-fold median increase) compared to that observed by Booker et al. (approximate 2-fold increase) ${ }^{26}$ and in the model developed by Aarons et al. ${ }^{14}$ As a result of rich sampling at early time points we observed a minor but consistent reduction in AAG concentrations in the immediate hours after the levobupivacaine, loading dose. This can be best described using an empirical precursor model, inhibiting AAG formation and simultaneously inducing precursor formation. This provides a reasonable description of the observed data. Care should be taken not to make inferences about the underlying mechanism based on this model.

Levobupivacaine displays linear binding to AAG, binding around $97 \% .{ }^{1}$ Concentration-dependent plasma protein binding with low to moderate hepatic extraction drugs such as levobupivacaine, will cause variation in total drug concentrations and associated pharmacokinetic parameters, whereas unbound concentrations and parameters will remain unaffected. ${ }^{8}$ Ideally, the unbound drug concentration should be measured as it drives pharmacological and toxicological effect. The inability to measure these data is an apparent limitation of the current study. However, a study protocol was devised to allow indirect inference of unbound levobupivacaine concentrations and unbound pharmacokinetic parameters by incorporating information on total levobupivacaine and AAG concentrations, and $\mathrm{K}_{\mathrm{D}}$, based on published adult data. ${ }^{24}$ 
The developed model was successful in describing the time-dependent change in total levobupivacaine concentrations due to changes in AAG and gave an indication of the unbound levobupivacaine concentration-time profile. Estimated $\mathrm{CLu} / \mathrm{F}$ was higher and $\mathrm{Vu} / \mathrm{F}$ was lower compared to that reported by Chalkiadis et al. ${ }^{8}$ This may be due several factors, including age differences of study participants in the two clinical trials (ontogeny of clearance) ${ }^{2}$ and differences in study duration ( $4 \mathrm{~h}$ versus $72 \mathrm{~h}$ here). Further, the approach detailed here is susceptible to uncertainty in the determination of $\mathrm{K}_{\mathrm{D}}$ and its ontogeny. ${ }^{24}$ Aarons et al. found $\mathrm{K}_{\mathrm{D}}$ of ropivacaine plasma protein binding to vary with age based on population pharmacokinetic analysis of unbound and total drug concentration-time profiles. ${ }^{14}$ It is therefore plausible that the AAG $\mathrm{K}_{\mathrm{D}}$ of levobupivacaine also may vary with age.

The pharmacokinetic model suggests that the unbound concentration of levobupivacaine quickly reaches steady state concentrations following a loading dose and is maintained at the same level for the duration of the infusion at the current rate. This is an average concentration of $0.03 \mathrm{mg} . \mathrm{L}^{-1}$ of unbound levobupivacaine throughout the infusion period. We also simulated an alternative dosing protocol $\left(2.5 \mathrm{mg} \cdot \mathrm{kg}^{-1}\right.$ loading dose followed immediately by a maintenance infusion of $0.2 \mathrm{mg} \cdot \mathrm{kg}^{-1} \cdot \mathrm{h}^{-1}$ ). Simulated concentration-time profiles (Figure 5) using this alternative dosing were very similar to the standard protocol and showed only a slight increase in unbound concentrations (remaining below $0.08 \mathrm{mg} \cdot \mathrm{L}^{-1}$ ). This protocol could reduce the need for opioid rescue analgesia in this age group when receiving a caudal-epidural, which is sometimes, required with the present local anaesthetic dosage limitations. However, further studies are needed to confirm this. Evidence suggests keeping serum total bupivacaine levels below $2-2.5 \mathrm{mg} . \mathrm{L}^{-1}$ to avoid toxicity. ${ }^{4}$ Levobupivacaine has an improved safety profile $1,6,7,8$ but there are no studies indicating unbound serum levobupivacaine toxic levels.

Some of the individual profiles indicated complex absorption kinetics from the epidural space. This would perhaps be best described using a combined slow and fast absorption rate as previously shown through modelling of epidural levobupivacaine in adults. ${ }^{27}$ The complex absorption was however only apparent in a small proportion of study participants and not significant enough to allow inclusion in the current model.

All infants required blood transfusion. The effect of blood transfusion is rarely considered in pharmacokinetic analysis and little is known about its impact on drug disposition. Although theoretically possible, no apparent trends were seen when comparing blood transfusion volumes to estimated individual pharmacokinetic parameters.

Clonidine is a common adjuvant to levobupivacaine in a single dose or caudal infusions. Clonidine was a noninvestigational medicinal product (NIMP) in this clinical trial and was used in a concentration of $1.5 \mathrm{mcg} \cdot \mathrm{mL}^{-1} \mathrm{based}$ on 
previous studies. ${ }^{13,17}$ Chalkiadis et al. ${ }^{17}$ indicated that levobupivacaine is more rapidly absorbed from the caudal-epidural space when clonidine is added. While we were not able to compare levobupivacaine absorption pharmacokinetics with and without clonidine, total serum concentrations of levobupivacaine were well below suggested toxic levels throughout the study.

One of the infants (infant 3 ) had to be excluded from data analysis as this infant was reintubated and caudal catheter removed at $12 \mathrm{~h}$ due to high grade pyrexia and respiratory distress. This was recorded as a serious adverse event (SAE). Viral and bacterial titres were negative and the infant was extubated after 48 hours. Pain scores, remained below 4 (FLACC) in all infants using prescribed rescue analgesia.

\section{Conclusions}

This trial has allowed the development of a pharmacokinetic model for the studied age group combining levobupivacaine and AAG data. The simulated concentration-time profiles show that unbound levobupivacaine concentrations reach an early steady state level following the loading dose and the simulated steady state concentrations are below suggested toxic concentrations. Hence it is possible to increase the duration of the infusion to more than 48 hours.

The current dosing recommendations may be too conservative when using levobupivacaine in the studied age group. However, over a broader age range, variation in elimination or a compromised liver function must be taken into consideration.

\section{Acknowledgements}

Department of Clinical Pathology, Queens Medical Centre, Nottingham University Hospitals NHS trust.

\section{Collaborators}

Department of Paediatric Urology, Royal Manchester Children’s Hospital:

Mr R Cervellione

Mr D Keene

\section{Funding}

Department of Paediatric Anaesthesia, Manchester University Foundation Trust.

Department of Paediatric Urology, Manchester University Foundation Trust. 


\section{Declaration of Interests}

None to declare.

\section{References}

1. Foster RH, Markham A. Levobupivacaine: a review of its pharmacology and use as a local anaesthetic. Drugs 2000;59:551-78.

2. Chalkiadis GA, Anderson BJ. Age and size are the major covariates for prediction of levobupivacaine clearance in children. Pediatr Anesth 2006;16:275 - 82.

3. Berde CB. Convulsions associated with pediatric regional anesthesia. Anesth Analg 1992;75:164-66.

4. Luz G, Innerhofer P, Bachmann B et al. Bupivacaine plasma concentrations during continuous epidural anesthesia in infants and children. Anesth Analg 1996;82:231-34.

5. McCloskey JJ, Haun SE, Deshpande JK. Bupivacaine toxicity secondary to continuous caudal epidural infusion in children. Anesth Analg 1992;75:287-90.

6. Cortinez LI, Fuentes R, Solari S et al. Pharmacokinetics of levobupivacaine (2.5 $\mathrm{mg} / \mathrm{kg})$ after caudal administration in children younger than 3 years. Anesth Analg 2008;107:1182-84.

7. Chalkiadis GA, Eyres RL, Cranswick N et al. Pharmacokinetics of levobupivacaine $0.25 \%$ following caudal administration in children under 2 years of age. Br J Anaesth 2004; 92:218-222.

8. Chalkiadis GA, Anderson BJ, Tay $\mathrm{M}$ et al. Pharmacokinetics of levobupivacaine after caudal epidural administration in infants less than 3 months age. Br J Anaesth 2005; 95:524 -29.

9. Lerman J, Nolan L et al. Efficacy, safety and pharmacokinetics of levobupivacaine with and without fentanyl after continous epidural infusion in children: a multicentre trial. Anesthesiology 2003; 99:1166-74.

10. Larsson BA, Olsson GL, Lonnqvist PA. Plasma concentrations of bupivacaine in young infants after continuous epidural infusion. Pediatr Anesth 1994;4:159-62.

11. Larsson BA, Lonnqvist PA, Olsson GL. Plasma concentrations of Bupivacaine in neonates after continuous epidural infusion. Anesth Analg 1997;84:501-05.

12. Cervellione RM, Mantovani A, Gearhart J et al. Prospective study on the incidence of bladder/cloacal exstrophy and epispadias in Europe. J Pediatr Urol 2015;11:337. 
13. Epidural Infusion pain management guideline, Royal Children's Hospital, Melbourne http://www.rch.org.au/anaes/pain_management/Epidural_Infusion. Updated 2017.

14. Aarons L, Sadler B, Pitsiu M et al. Population pharmacokinetic analysis of ropivacaine and its metabolite 2', 6'pipecoloxylidide from pooled data in neonates, infants, and children. Br J Anaesth 2011;107:409-24.

15. Howie SRC. Blood sample volumes in child health research: review of safe limits. Bull World Health Organ 2011;89:46-53.

16. Gueorguieva I, Ogungbenro K, Graham G et al. A program for individual and population optimal design for univariate and multivariate response pharmacokinetic-pharmacodynamic models. Comput Methods Programs Biomed 2007;86:51-61.

17. Chalkiadis GA, Abdullah F, Bjorksten AR et al. Absorption characteristics of epidural levobupivacaine with adrenaline and clonidine in children. Pediatr Anesth 2013; 23: 58-67.

18. Moffatt AC, Osselton BM. Clarke's Isolation and Identification of Drugs-Third Edition, Pharmaceutical Press 2004

19. Lindberg RLP, Pihlajamäki KK. High performance liquid chromatographic determination of bupivacaine in human serum. J Chromatogr 1984,309:369-374.

20. R Core Team (2013). R: A language and environment for statistical computing. R Foundation for Statistical Computing, Vienna, Austria. http://R-project.org/.

21. Bellu G, Saccomani MP, Audoly S et al. DAISY: a new software tool to test global identifiability of biological and physiological systems. Comput Methods Programs Biomed 2007;88:52-61.

22. Keizer RJ, Jansen RS, Rosing H et al. Incorporation of concentration data below the limit of quantification in population pharmacokinetic analyses. Pharmacology research \& perspective. 2015;3: e00131.

23. Brill MJE, Välitalo PJA, Ramshorst BV et al. Semiphysiologically based pharmacokinetic model for midazolam and CYP3A mediated metabolite 1-OH-midazolam in morbidly obese and weight loss surgery patients. $C P T$ Pharmacometrics Syst Pharmacol. 2015;5:20-30.

24. Veering BT, Burm AG, Feyen HM et al. Pharmacokinetics of bupivacaine during postoperative epidural infusion enantioselectivity and role of protein binding. Anesthesiology 2002;96:1062-69.

25. Kost-Byerly S, Jackson EV, Yaster M et al. Perioperative anesthetic and analgesic management of newborn bladder exstrophy repair. J Pediatr Urol 2008;4:280-85.

26. Booker PD, Taylor C, Saba C. Perioperative changes in $\alpha_{1}$-acid glycoprotein concentrations in infants undergoing major surgery. Br J Anaesth; 1996:76:365-68. 
Table:

27. Olofsen E, Burm AGL, Simon MJG et al. Population Pharmacokinetic-Pharmacodynamic modelling of epidural anesthesia. Anesthesiology 2008;109:664-74.

\begin{tabular}{llll}
\hline Parameter & Estimate & \%BSV & 95\%Cl \\
\hline AAG parameters & & & \\
$\mathrm{CL}_{0}\left(\mathrm{~L}^{-1}\right)$ & 0.136 & - & $0.125,0.141$ \\
$\mathrm{C}(0)\left(\mathrm{mg} . \mathrm{L}^{-1}\right)$ & 413 & 31.2 & 292,475 \\
$\mathrm{INT}$ & 4.58 & 54.6 & $3.50,5.13$ \\
Err prop (\%) & 7.81 & - & $4.25,14.34$ \\
Levobupivacaine parameters & & & \\
$\mathrm{k}_{\mathrm{a}}\left(\mathrm{h}^{-1}\right)$ & 0.15 & - & $0.138,0.156$ \\
$\mathrm{~V}_{\mathrm{u}} / \mathrm{F}(\mathrm{L})$ & 1.05 & - & $0.62,1.27$ \\
$\mathrm{CL}_{\mathrm{u}} / \mathrm{F}\left(\mathrm{L} \cdot \mathrm{h}^{-1}\right)$ & 61.3 & 28.1 & $48.1,68.0$ \\
$\mathrm{~K}_{\mathrm{D}}\left(\mathrm{mg} \cdot \mathrm{L}^{-1}\right)$ & 32.6 & - & fixed \\
Err prop $(\%)$ & 33.0 & - & $12.15,89.72$ \\
\hline
\end{tabular}

$\mathrm{CL}_{0}=$ conversion clearance; $\mathrm{C}(0)=$ concentration of AAG and pre-AAG at time zero; INT $=$ interaction term; $\mathrm{k}_{\mathrm{a}}=$ firstorder absorption rate; $\mathrm{V}_{\mathrm{u}} / \mathrm{F}=$ apparent unbound volume of distribution; $\mathrm{CL}_{\mathrm{u}} / \mathrm{F}=$ apparent unbound clearance; $\mathrm{BSV}=$ interindividual variability presented as $\% \mathrm{CV}$ (coefficient of variation); Err prop = proportional residual variability; $95 \%$ CI are the $95 \%$ confidence intervals.

Table 1: $\alpha_{1}$-acid glycoprotein (AAG) dynamic model and levobupivacaine pharmacokinetic model, final parameter estimates. 


\section{$\underline{\text { LEGENDS FOR FIGURES }}$}

Figure 1. Schematic of final model. The model describes time-dependent changes in total levobupivacaine $\left(\mathrm{C}_{\text {tot,LBU }}\right)$ as dependent on unbound levobupivacaine concentrations $\left(\mathrm{C}_{\mathrm{u}, \mathrm{LBU}}\right), \alpha_{1}$-acid glycoprotein $\left(\mathrm{C}_{\mathrm{AAG}}\right)$ and the binding isotherm $\left(\mathrm{k}_{\mathrm{D}}\right) . \mathrm{R}_{0}=$ rate of infusion, $\mathrm{k}_{\mathrm{a}}=$ absorption rate, $\mathrm{CL}_{\mathrm{u}}=$ unbound apparent clearance, $\mathrm{CL}_{0}=$ formation clearance of pre- $\mathrm{AAG}$, conversion clearance from pre-AAG, elimination clearance of AAG. $\mathrm{C}_{\text {Pre-AAG }}=\mathrm{AAG}$ precursor.

Figure 2. Measured levels of total levobupivacaine concentration $\left(\mathrm{C}_{\mathrm{tot}, \mathrm{LBU}}\right)$ over time. Visual predictive check of total levobupivacaine concentration over time. Observed data indicated by (o), observed median data indicated by (--), median, $95^{\text {th }}$ and $5^{\text {th }}$ percentiles of model simulations indicated by $(-)$ and grey area.

Figure 3. $\alpha_{1}$-acid glycoprotein $(\mathrm{AAG})$ concentration $\left(\mathrm{C}_{\mathrm{AAG}}\right)$ over time. Visual predictive check of $\mathrm{AAG}$ concentration over time. Observed data indicated by (o), observed median data indicated by (--), median $95^{\text {th }}$ and $5^{\text {th }}$ percentiles of model simulations indicated by (-) and grey area

Figure 4. Simulated total $(A)$ and unbound $(B)$ concentration-time profiles of levobupivacaine $\left(C_{t o t, L B U}\right.$ and $C_{u, L B U}$, respectively) at the current dosing schedule. C: simulated $\alpha_{1}$-acid glycoprotein concentration $\left(\mathrm{C}_{\mathrm{AAG}}\right)$ over 72 hours. Median, $95^{\text {th }}$ and $5^{\text {th }}$ percentiles of model simulations indicated by (-) grey area.

Figure 5. Simulated total $(A)$ and unbound $(B)$ concentration-time profiles of levobupivacaine $\left(C_{t o t, L B U}\right.$ and $C_{u, L B U}$, respectively) at an alternative dosing protocol. C: $\alpha_{1}$-acid glycoprotein concentration over 72 hours. Median, $95^{\text {th }}$ and $5^{\text {th }}$ percentiles of model simulations indicated by (-) and grey area. 

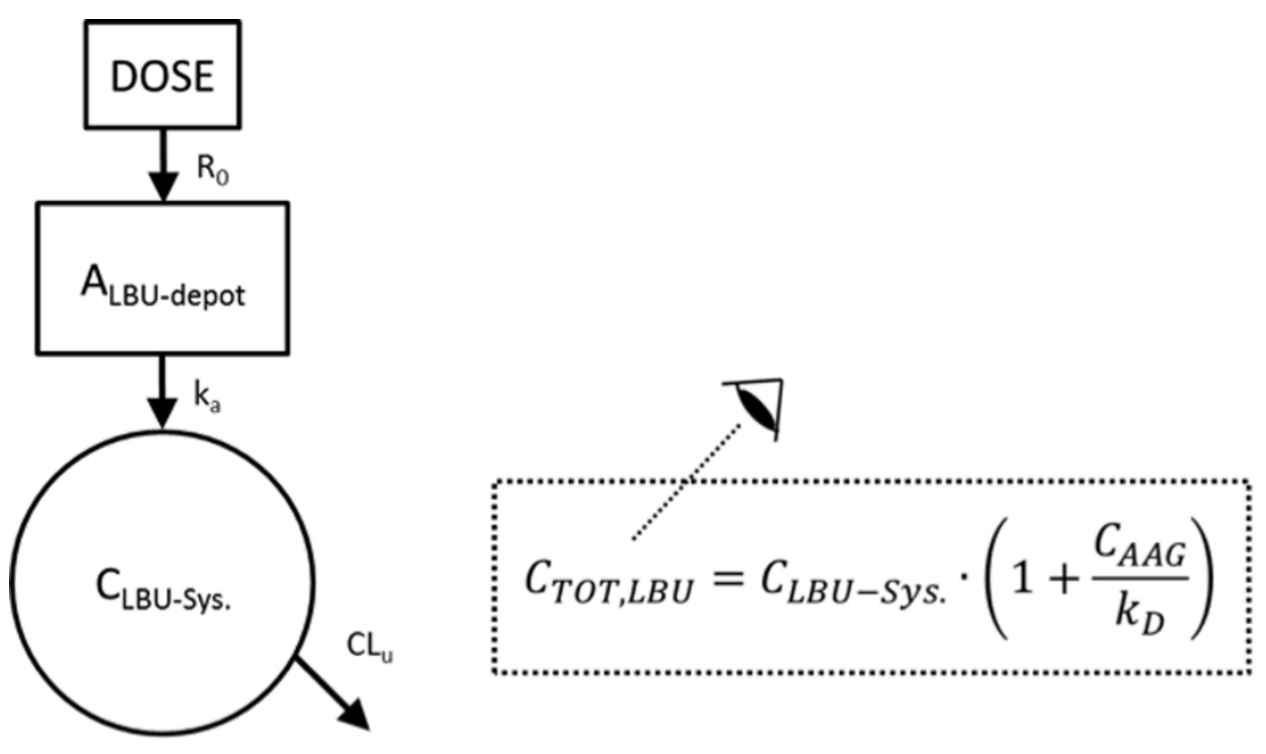

\section{INTERACTION (INT)}

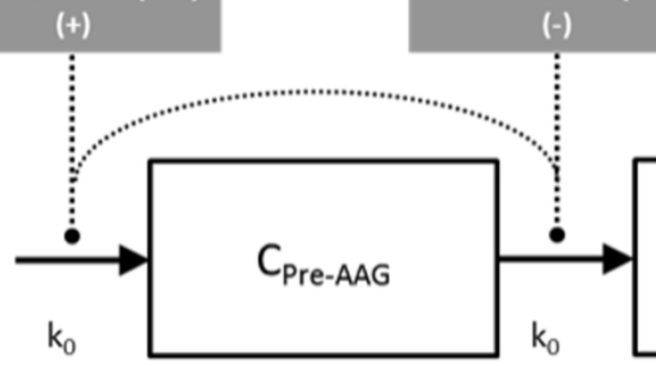

INTERACTION (INT)

\section{m}
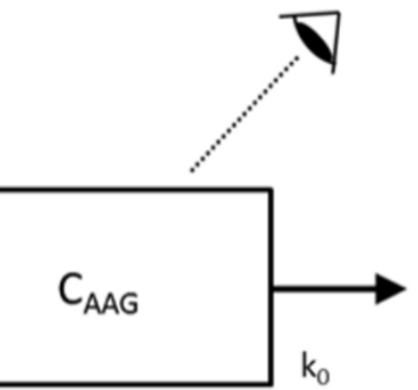

Figure 1. Schematic of the final model. The model describes time-dependent changes in total levobupivacaine (Ctot,LBU) as dependent on unbound levobupivacaine concentrations (Cu,LBU), a1-acid glycoprotein (CAAG) and the binding isotherm ( $k D)$. $R 0=$ rate of infusion, ka=absorption rate, $C L u=u n b o u n d$ apparent clearance, $\mathrm{CLO}=$ formation clearance of pre-AAG, conversion clearance from pre-AAG, elimination clearance of AAG. CPre-AAG=AAG precursor.

$107 \times 104 \mathrm{~mm}(300 \times 300 \mathrm{DPI})$ 


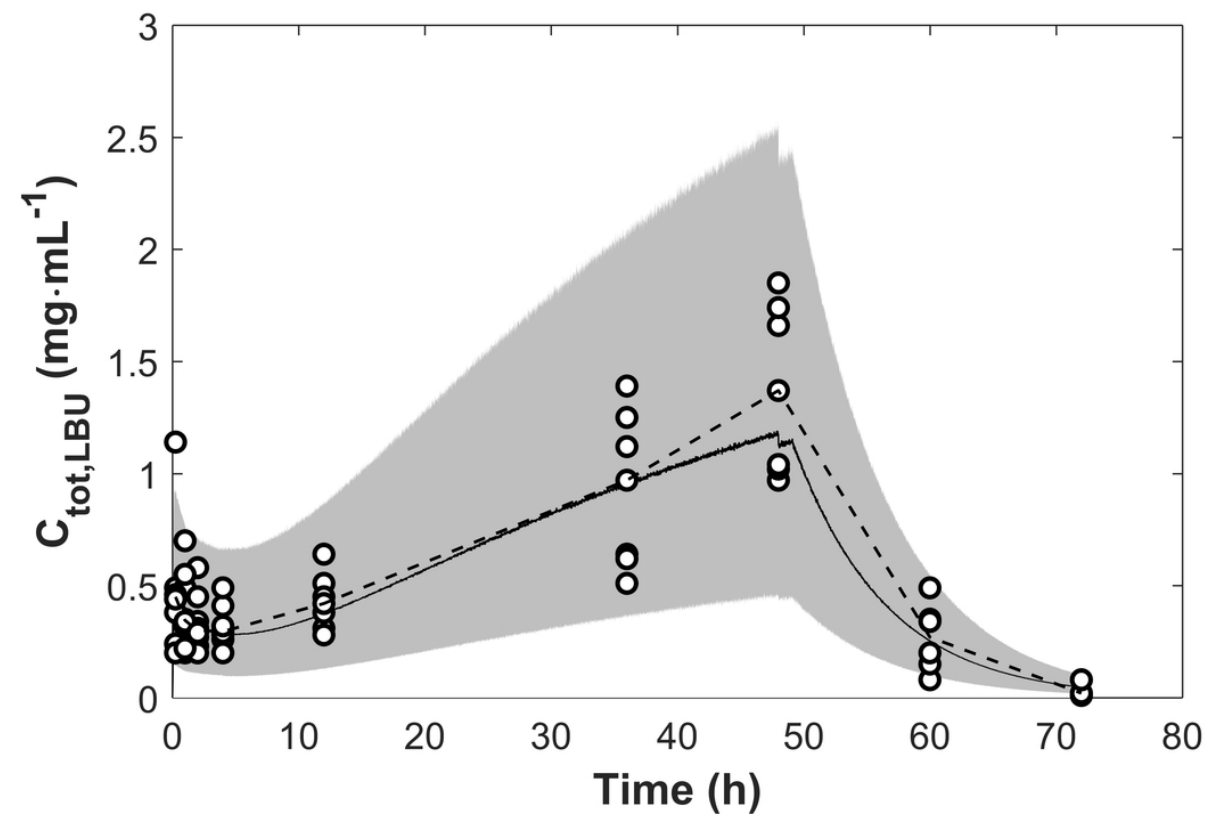

Figure 2. Measured levels of total levobupivacaine concentration (Ctot,LBU) over time. Visual predictive check of total levobupivacaine concentration over time. Observed data indicated by (o), observed median data indicated by $(--)$, median, 95 th and 5th percentiles of model simulations indicated by (-) and grey area. 


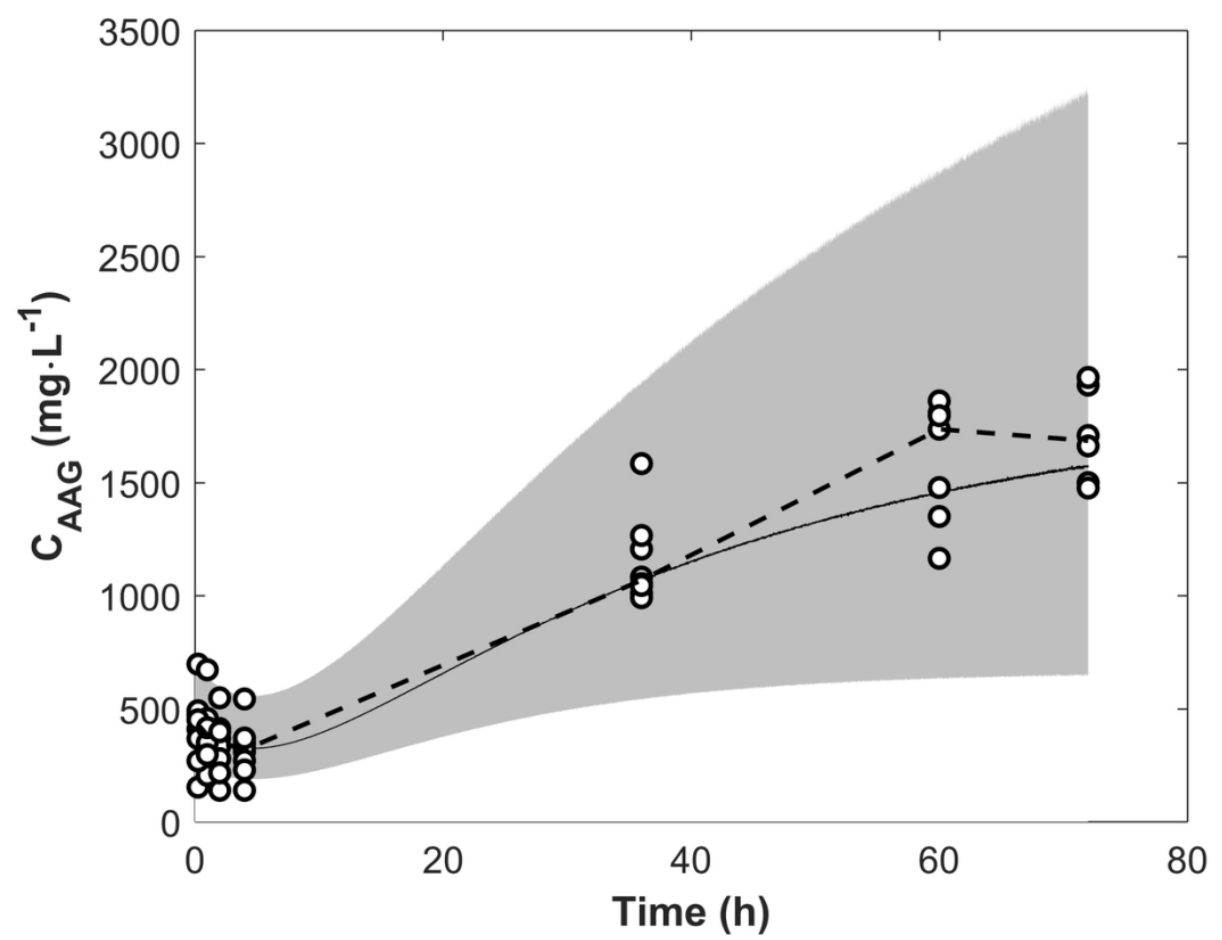

Figure 3. a1-acid glycoprotein (AAG) concentration (CAAG) over time. Visual predictive check of AAG concentration over time. Observed data indicated by (0), observed median data indicated by (--), median, 95 th and 5 th percentiles of model simulations indicated by $(-)$ and grey area 
Figure 4. Simulated total (A) and unbound (B) concentration-time profiles of levobupivacaine (Ctot, LBU and $\mathrm{Cu}, \mathrm{LBU}$, respectively) at the current dosing schedule. C: simulated a1-acid glycoprotein concentration (CAAG) over 72 hours. Median, 95th and 5th percentiles of model simulations indicated by (-) grey area. 

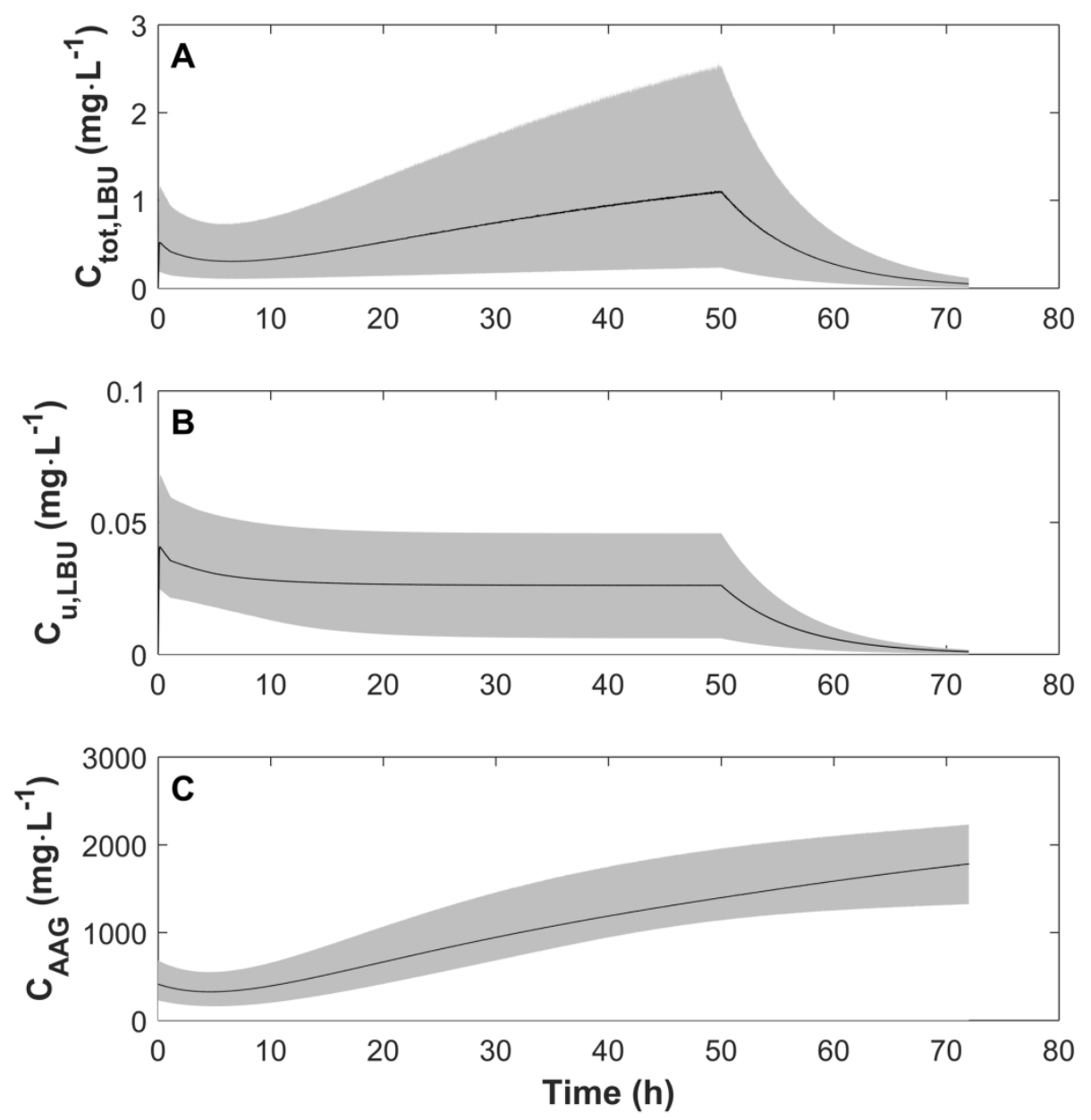

Figure 5. Simulated total (A) and unbound (B) concentration-time profiles of levobupivacaine (Ctot, LBU and Cu,LBU, respectively) at an alternative dosing protocol. C: a1-acid glycoprotein concentration over 72 hours. Median, 95th and 5th percentiles of model simulations indicated by (-) and grey area.

$176 \times 185 \mathrm{~mm}(300 \times 300$ DPI $)$ 


\section{Supplementary material}

\section{A Study Of The Dosage And Duration For Levobupivacaine Infusion By The Caudal-Epidural Route In}

\section{Infants Aged 3-6 Months}

Rita Vashisht ${ }^{1}$, Anju A. Bendon ${ }^{1}$, Ijeoma Okonkwo ${ }^{1}$, Davandra Patel ${ }^{1}$, Catherine Fullwood ${ }^{2}$, Kayode

Ogungbenro $^{3}$, Leon Aarons ${ }^{3}$, Adam S. Darwich ${ }^{3}$

${ }^{1}$ Department of Paediatric Anaesthesia, Royal Manchester Children's Hospital, Manchester University NHS Foundation Trust, Manchester, United Kingdom; ${ }^{2}$ Research and Innovation; Biostatistics, Nowgen Building, Manchester, United Kingdom; ${ }^{3}$ Centre for Applied Pharmacokinetic Research, School of Health Sciences, The University of Manchester, United Kingdom.

\section{Determining the dissociation constant for levobupivacaine binding to $\alpha_{1}$-acid glycoprotein}

The plasma protein binding dissociation constant $\left(\mathrm{K}_{\mathrm{D}}\right)$ between levobupivacaine (LBU) and $\alpha_{1}$-acid glycoprotein (AAG) was determined based on the measured fraction unbound in plasma $\left(f u_{p}\right)$ and $A A G$ concentrations $\left(C_{A A G}\right)$ reported in eight adult patients as per Veering et al., 2002 (Figure 2 in Veering et al., 2002) ${ }^{1}$. The data was digitised using GetData Digitizer and analysed in Microsoft Excel. $\mathrm{K}_{\mathrm{D}}$ was calculated for each individual data point based on Equation $\mathrm{S} 1$, where $C_{u}$ is the measured unbound concentration and $C$ the total concentration of LBU, and $C_{A A G}$ is the concentration of AAG. The geometric mean $\mathrm{K}_{\mathrm{D}}$ was determined to be $32.6 \mathrm{mg} . \mathrm{L}^{-1}$ with a geometric standard deviation of $\mathrm{mg} \cdot \mathrm{L}^{-1}$. Using the determined $\mathrm{K}_{\mathrm{D}}$, a mean absolute error (MAE) of 0.7 was given (Figure S1).

$$
C_{u}=C \cdot \frac{1}{1+\frac{C_{A A G}}{K_{D}}} \text {, where } f u_{p}=\frac{C_{u}}{C}, K_{D}=-\frac{f u_{p} \cdot C_{A A G}}{f u_{p}-1}
$$

\section{Equation S1}

\section{Prospective prediction of levobupivacaine}

Figure S2 shows bodyweight, age and dose-matched simulations of average AAG, total and unbound levobupivacaine concentrations $\left(\mathrm{C}_{\mathrm{tot}, \mathrm{LBU}}\right.$ and $\mathrm{C}_{\mathrm{u}, \mathrm{LBU}}$, respectively) using the prospectively developed model based on Chalkiadis et al., $2005^{2}$ and Aarons et al., $2000^{3}$ to inform optimal design of the clinical study sampling time points. 


\section{Model equations for $\alpha_{1}$-acid glycoprotein and levobupivacaine}

The final AAG-LBU model is presented in Equations S2-S6. The AAG model that produced the best fit to the observed AAG data, meaning it was able to describe the initial reduction and subsequent increase in AAG concentration, was a precursor model with positive feedback. The model described time dependent concentrations of a theoretical precursor of AAG $\left(C(t)_{p r e-A A G}\right.$; Equation S2) and AAG $\left(C(t)_{A A G}\right.$; Equation S3). The production and elimination clearances of AAG and its precursor were equal to $C L_{0}$, meaning these clearances rates were assumed to be equal across the two states and at time zero the initial concentrations of $C(0)_{\text {pre-AAG }}$ and $C(0)_{A A G}$ were set to equal $C_{0}$. Further, a static interaction constant (INT) was estimated, meaning it did not vary over time. INT acted in the model by inhibiting pre-AAG conversion to AAG and simultaneously inducing preAAG production at the same magnitude throughout the study time period. Prior to parameter estimation of $C L_{0}$, $C_{0}$ and $I N T$, the model was evaluated in the software DAISY to test global identifiability. The model developed for the AAG data should be viewed as an empirical description of the AAG levels and no mechanistic interpretation is implied.

$\frac{d C_{p r e-A A G}}{d t}=C_{0} \cdot C L_{0} \cdot I N T-C(t)_{p r e-A A G} \cdot C L_{0} / I N T$ $C(t=0)_{\text {Pre }-A A G}=C_{0}$

\section{Equation S2}

$$
\frac{d C_{A A G}}{d t}=C(t)_{p r e-A A G} \cdot C L_{0} / I N T-C(t)_{A A G} \cdot C L_{0} \quad C(t=0)_{A A G}=C_{0}
$$

\section{Equation S3}

Unbound amount of LBU $\left(A(t)_{u, L B U}\right)$ was modelled using a one-compartment model with first-order absorption rate $\left(k_{a}\right)$ from the dosing compartment $\left(A(t)_{\text {LBU-depot }}\right)$ with linear elimination $\left(C L_{u} / V_{u}\right)$. Unbound levobupivacaine concentrations $\left(C(t)_{u, L B U}\right)$ were then converted to total concentrations $\left(C(t)_{t o t, L B U}\right)$ using an assumed linear relationship $\left(K_{D}\right)$ based on adult data as per Veering et al. $2000^{1}$ (Equations S4-S6). In Equation 6, is shown the simplification of the conversion of $C(t)_{u, L B U}$ to $C(t)_{t o t, L B U}$ when assuming $C_{u, L B U}$ to be significantly smaller as compared to $K_{D}$.

$\frac{d A_{L B U, \text { depot }}}{d t}=-k_{a} \cdot A(t)_{L B U, \text { depot }}$

\section{Equation S4}


$\frac{d A_{u, L B U}}{d t}=k_{a} \cdot A(t)_{L B U, \text { depot }}-A(t)_{u, L B U} \cdot \frac{C L_{u}}{V_{u}} \quad C(t)_{u, L B U}=\frac{C(t)_{u, L B U}}{V_{u}}$

\section{Equation S5}

$C(t)_{t o t, L B U}=C(t)_{u, L B U} \cdot\left(1+\frac{C(t)_{A A G}}{C(t)_{u, L B U}+K_{D}}\right), C_{u, L B U} \ll K_{D}, C(t)_{t o t, L B U}=C(t)_{u, L B U} \cdot\left(1+\frac{C(t)_{A A G}}{K_{D}}\right)$

\section{Equation $\mathrm{S6}$}

\section{Final model parameter estimates}

Final model parameter estimates are given in for the AAG model, in Table S1, and for the levobupivacaine model in Table S2.

\section{Goodness-of-fit plots}

Goodness-of-fit plots for the AAG and levobupivacaine models are shown in Figure S3.

\section{References}

1. Veering BT, Burm AGL, Feyen HM et al. Pharmacokinetics of bupivacaine during postoperative epidural infusion. Anesthesiology 2002;96:1062-1069.

2. Chalkiadis GA, Anderson BJ, Tay M et al. Pharmacokinetics of levobupivacaine after caudal epidural administration in infants less than 3 months of age. Br J Anaesth 2005;95:524-529.

3. Aarons L, Sadler B, Pitsiu M et al. Population pharmacokinetic analysis of ropivacaine and its metabolite 2',6'-pipecoloxylidide from pooled data in neonates, infants, and children. Br J Anaesth 2011;107(3):409-424

\section{Tables:}




\begin{tabular}{|c|l|l|l|l|l|l|l|l|l|}
\hline Time (hours) & 0.25 & 1 & 2 & 4 & 12 & 36 & 48 & 60 & 72 \\
\hline $\begin{array}{c}\text { AAG: } \\
0.8 \text { mL per sample }\end{array}$ & 1 & 1 & 1 & 1 & $\begin{array}{l}\text { No } \\
\text { sample }\end{array}$ & 1 & $\begin{array}{l}\text { No } \\
\text { sample }\end{array}$ & 1 & 1 \\
\hline LBU: $2 \mathrm{~mL}$ per sample & 1 & 1 & 1 & 1 & 1 & 1 & 1 & 1 & 1 \\
\hline
\end{tabular}

Table S1: Blood sampling schedule for levels of $\alpha_{1}$-acid glycoprotein (AAG) and levobupivacaine (LBU).

\section{Figure Legends}

Figure S1. Fraction unbound levobupivacaine in plasma $\left(\mathrm{fu}_{\mathrm{p}}\right)$ against concentration of $\alpha_{1}$-acid glycoprotein $\left(\mathrm{C}_{\mathrm{AAG}}\right)$. Observed data (o) digitised from Veering et al., 2002 (1), dashed line (--) indicate model prediction at $\mathrm{K}_{\mathrm{D}}=32.6 \mathrm{mg} \cdot \mathrm{L}^{-1} . \mathrm{K}_{\mathrm{D}}$ : geometric mean plasma protein binding dissociation constant, GSD: geometric standard deviation, MAE: mean absolute error

Figure S2. Simulated and observed levobupivacaine (LBU) and $\alpha_{1}$-acid glycoprotein (AAG) concentration-time profiles based on prospective predictions using the model intended for optimal design. A: Simulated unbound plasma concentration of levobupivacaine $\left(\mathrm{C}_{\mathrm{u}, \mathrm{LBU}}\right)$, B: Simulated (-) and observed (o) total plasma concentration of levobupivacaine $\left(\mathrm{C}_{\text {tot,LBU }}\right)$, C: simulated (-) and observed (o) AAG levels $\left(\mathrm{C}_{\mathrm{AAG}}\right)$, D: Simulated fraction unbound $\left(\mathrm{fu}_{\mathrm{p}}\right)$ of levobupivacaine over time.

Figure S3. Goodness-of-fit plots for $\alpha_{1}$-acid glycoprotein (A, C, E) and total levobupivacaine (B, D, F), respectively. 


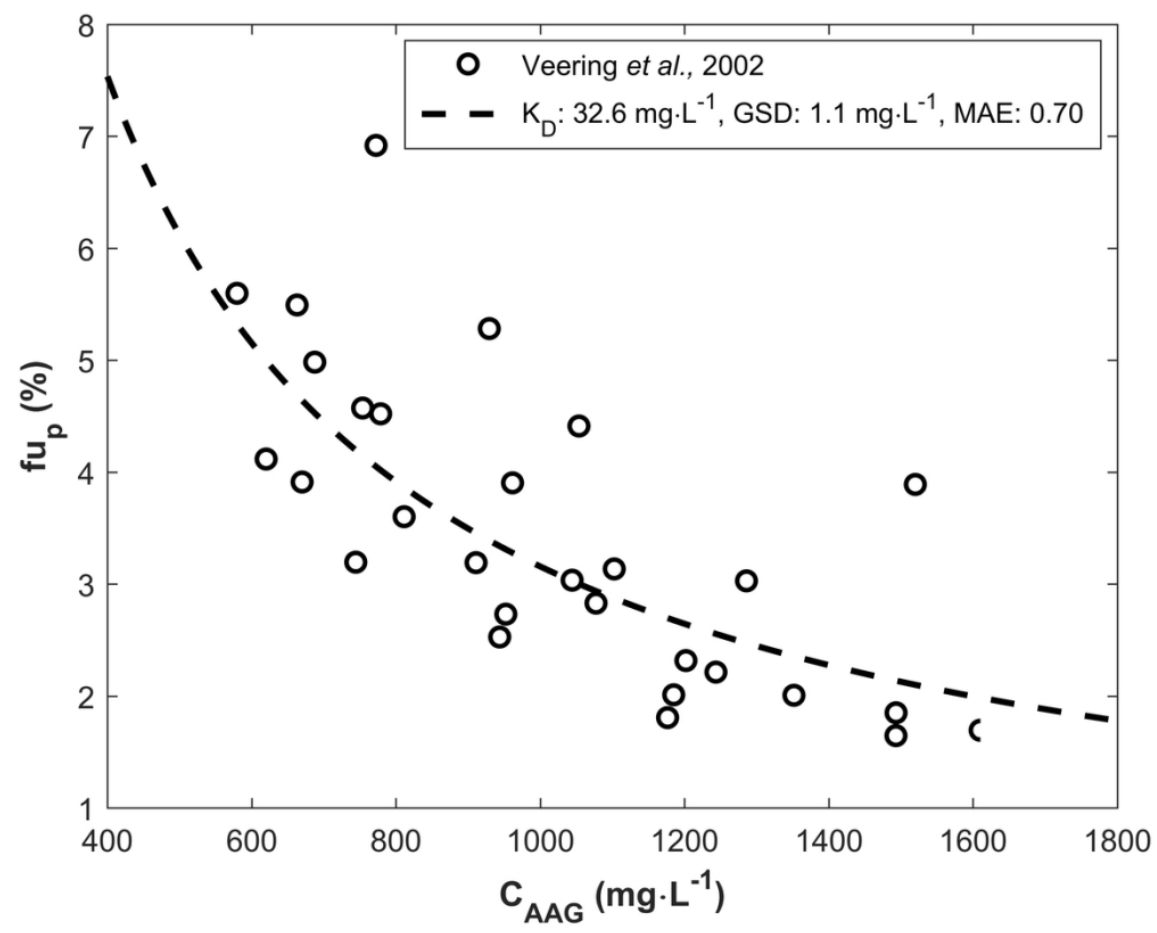

Figure S1. Fraction unbound levobupivacaine in plasma (fup) against concentration of a1-acid glycoprotein (CAAG). Observed data (o) digitised from Veering et al., 2002 (1), dashed line (--) indicate model prediction at $\mathrm{KD}=32.6 \mathrm{mg} . \mathrm{L}-1$. KD: geometric mean plasma protein binding dissociation constant, GSD: geometric standard deviation, MAE: mean absolute error

$$
111 \times 83 \mathrm{~mm}(300 \times 300 \mathrm{DPI})
$$



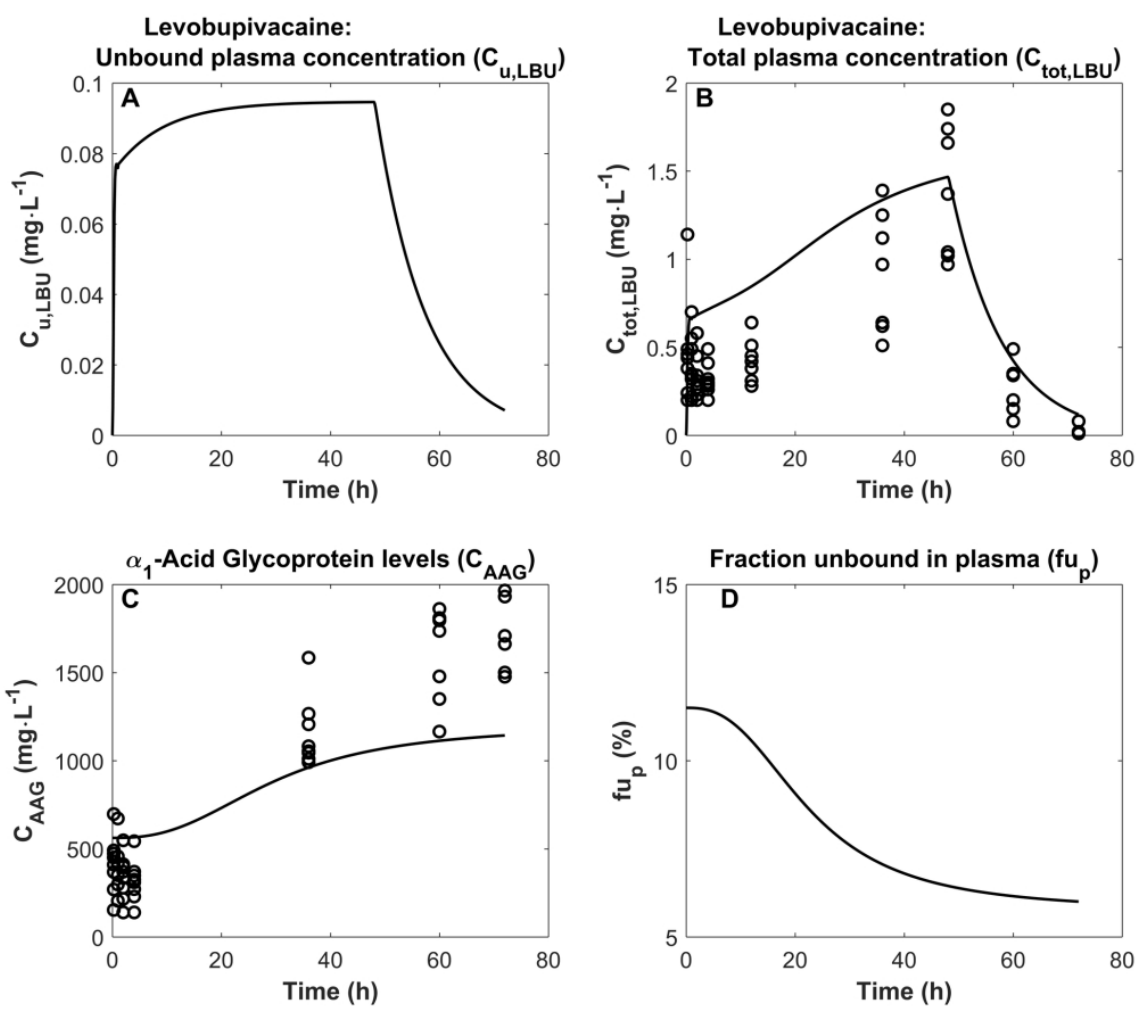

Figure S2. Simulated and observed levobupivacaine (LBU) and a1-acid glycoprotein (AAG) concentrationtime profiles based on prospective predictions using the model intended for optimal design. A: Simulated unbound plasma concentration of levobupivacaine (Cu,LBU), B: Simulated (-) and observed (o) total plasma concentration of levobupivacaine (Ctot,LBU), C: simulated (-) and observed (o) AAG levels (CAAG), D: Simulated fraction unbound (fup) of levobupivacaine over time

$199 \times 162 \mathrm{~mm}(300 \times 300 \mathrm{DPI})$ 

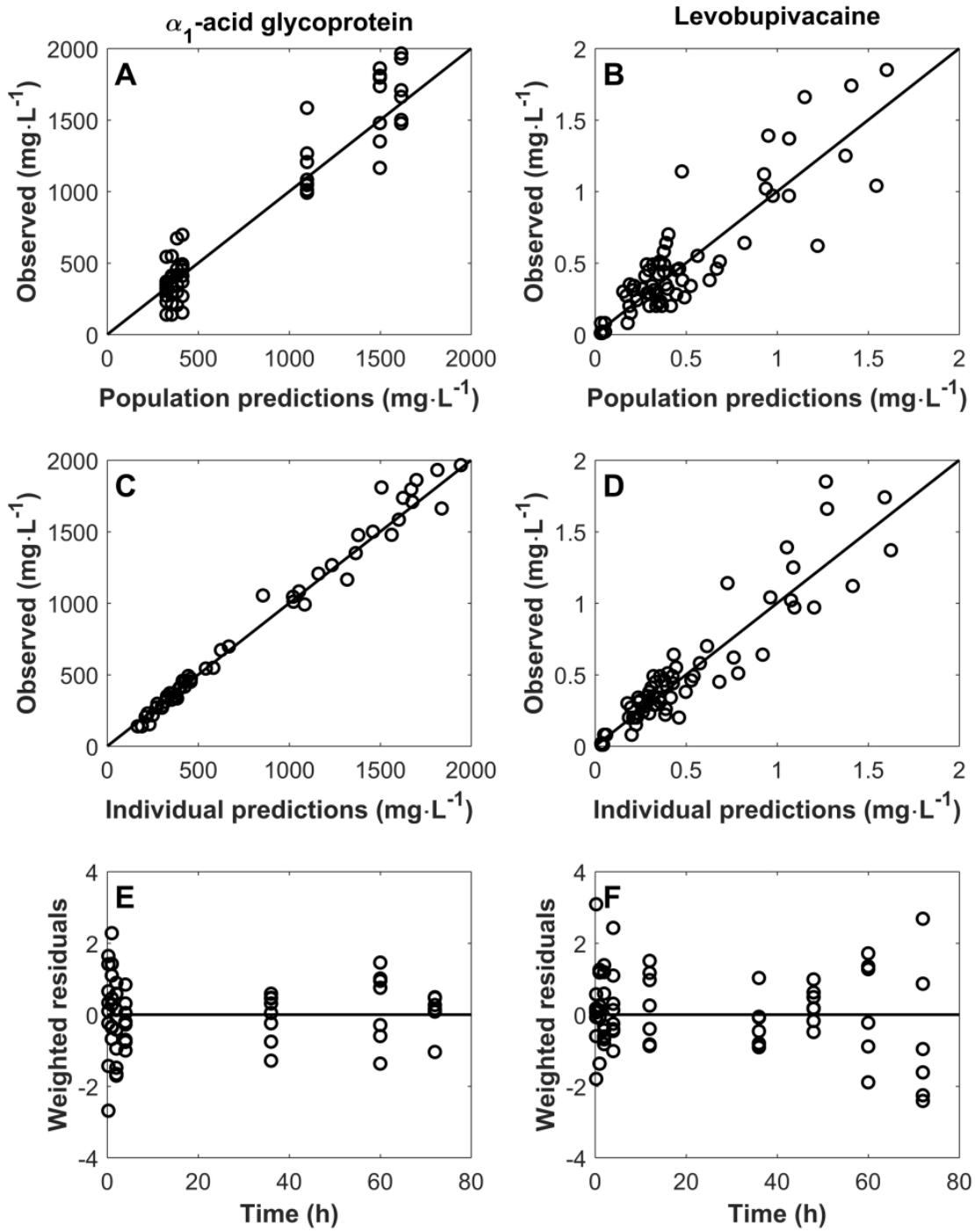

Figure S3. Goodness-of-fit plots for a1-acid glycoprotein (A, C, E) and total levobupivacaine (B, D, F), respectively.

$250 \times 310 \mathrm{~mm}(300 \times 300 \mathrm{DPI})$ 